\title{
Twenty Years on for The Epithelial-Mesenchymal Transition International Association (TEMTIA): An Interview with Co-Founders Erik Thompson and Donald Newgreen
}

\author{
Guojun Sheng $^{\mathrm{a}}$ Erik Thompson ${ }^{\mathrm{b}}$ Donald Newgreen ${ }^{c}$ Hans-Werner Denker ${ }^{\mathrm{d}}$ \\ anternational Research Center for Medical Sciences, Kumamoto University, Kumamoto, Japan; bSchool of \\ Biomedical Sciences and Translational Research Institute, Queensland University of Technology, Brisbane,

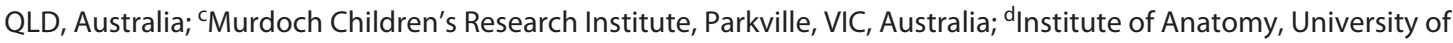 \\ Duisburg-Essen, Essen, Germany
}

\section{Keywords}

Epithelial-mesenchymal transition - TEMTIA - Breast cancer . Neural crest $\cdot$ Implantation

\section{Background}

For more than 50 years after its inception, epithelialmesenchymal transition (EMT) research has been catalyzed by cross-disciplinary interactions between developmental, cell, and cancer biologists. Among those, two Australian scientists, Erik Thompson, a cancer biologist, and Donald Newgreen, a developmental biologist, played an instrumental role in steering this research community towards its current state of full blossom. They co-founded "The EMT International Association" (TEMTIA), co-organized the first TEMTIA meeting, bringing together researchers of different background, and despite divergence in their scientific approaches, they have been coadvocating the need for breakthrough discoveries on EMT-based therapeutic intervention in fighting cancer. In its early days, EMT research also caught the attention of Hans-Werner Denker, a German developmental biologist. Through his role as Editor-in-Chief of Cells Tissues
Organs (formerly known as Acta Anatomica), Dr. Denker pushed for the publication of a two-volume EMT-focused special topic issue in 1995/1996, consolidating the status of EMT as a formidable research discipline. Many of those who contributed to that first EMT special issue and who attended the first TEMTIA meeting became leaders and strong advocates of EMT research. In this interview, Dr. Thompson and Dr. Newgreen reminisce about their own career trajectories and about that of EMT, and offer advice on where this field should be heading, together with comments from Dr. Denker. The hope is that new generations of EMT researchers, less afraid of crossing disciplinary boundaries, will bring conceptual clarity, EMT-based and experimentally actionable, to complex biological phenomena in development and disease.

\section{Interview}

G.S.: What got you into science and into EMT research in the first place?

Rik: My dad worked as a medical laboratory technologist at the Hospital and then in a University medical research laboratory, so I was hooked on medical research 
from the get-go. I had an unexplained interest and passion to work in cancer, which I continue to this day, but there was no cancer at my university for my undergraduate or PhD years. I had to wait until my postdoc at NIH with George Martin and Hynda Kleinman, where I studied basement membrane invasion of cancer cells using Matrigel. I got into EMT because I was studying the hormonal regulation of invasion and metastasis of breast cancer cell lines, and using an ER-negative cell line as the control. It was highly invasive, as were several others that I tested. Fortunately for me, Connie Sommers at Lombardi Cancer Centre, Georgetown had undertaken a subtractive hybridization gene expression screen between these same cell lines and identified vimentin as a very strong hit, which Steve Byers recognised as an EMT marker - he taught embryology! They were very generous and gracious in sharing their work, and allowing me to continue on what became a career in EMT research [Thompson et al., 1992]. My good luck did not stop there; I was so fortunate that Christine Gilles chose to work with me as a postdoctoral fellow and brought her own interest and passion for EMT arising from her graduate studies in lung cancer; we continue to collaborate between Australia and Belgium to this day. I also could not have been more fortunate then to move to Melbourne and discover Don Newgreen at a seminar given by Leigh Ackland in a neighbouring Institute. Don, Leigh, and I worked together for many years on the PMC42 system that Leigh had characterized [Ackland et al., 2003], and brought together what became TEMTIA.

Don: As a child I'd always been obsessively interested in animals and how they worked, but biology was not offered at my school - and I knew no one who worked in science of any discipline to advise me as to what was possible. I was clueless; so not much has changed. I enrolled in dentistry (future income $\uparrow$, excitement $\downarrow$ ) at University of Melbourne but found it intellectually unchallenging so I switched to science (future income $\downarrow$, excitement $\uparrow$ ), majoring in Zoology and Physiology. This was a good decision because it fitted what I'd always been interested in. In my B.Sc. third undergraduate year, I took courses in nervous system development and in "classic" developmental biology (by Mr. Alistair Willis, in Zoology - no $\mathrm{PhDs}$ required then). I was transfixed by how nerves migrated to their target. I then came across Jim Weston's new review [Weston, 1970] on the neural crest, and I thought: This is the same navigation question but cells must be bigger than growth cones -so they might be easier to study! Jim and Nicole Le Douarin were the crest gods at the time, but their work focused mainly on cell differentiation. So I started to "do" cell migration on my own. Right from the start the obvious questions were: How do neural crest cells start migration? (EMT!). How do they move singly and socially? How do they find their way? How do they stop in the "right" region?

With the arrogance of ignorance, I jumped right into this experimentally in the Zoology Department in 1971 as a 1-year Honours research project. This then led to a doctoral project, which I made up as I went along. I was fortunate that Geoff Burnstock's Zoology Department had an autonomic nervous system focus with post-doc neurophysiologists like Marcello Costa and John Furness. More importantly, Gerda Mark had just set up a tissue culture lab next door to my room (sometimes laughingly described as a lab). Without this technical knowledge and equipment (such as $16 \mathrm{~mm}$ time lapse phase contrast micrography - state of the art!), progress would have been zero. It was at this time that I stumbled on a simple in vitro set-up that allowed neural crest EMT and migration to be studied. This facilitated both observation and experimentation, and was the basis of most of my work on EMT over the next decades.

The past is a different country; it was possible then, as a student, to be permitted to embark on a line of research without a supervisor working in that line (and shortly, without a supervisor at all), and with virtually nobody working on such morphogenesis questions anywhere in the world. I benefited enormously from ad hoc collaborations with fellow students like Ian Allan, Michael Ritterman, Elisabeth Peters, Ian Gibbins, Heather Young, and Bridget Southwell, each more or less supervising the other. So, I've spent about 50 years doing my undergraduate project.

G.S.: You are founding members of TEMTIA. Can you tell us why and how you started TEMTIA?

Rik: As mentioned above, Don and I started to work together in the late 1990s and collectively we had a good appreciation of the EMT field in Development and Cancer, respectively. After a year or two, Don proclaimed "We should have an EMT conference!", which I of course thought was a great idea - I do love a good conference! This led to the first International EMT meeting in Port Douglas, Australia (do look it up!) in 2003, for which we created The International EMT Association/TEMTIA (Don thought TEMTIA rolled off the tongue in a tempting way) in 2002 (Fig. 1). A wonderful international committee (Fig. 2) assisted us to pull this meeting together, and we obtained the only conference support available in Australia, a prestigious Boden meeting status and small grant (Fig. 3). Also important was the inimitable Ros (Barrett-Lennard) from 
Fig. 1. Certificate of incorporation of TEMTIA as a scientific association in 2002.

\section{- \\ NSW Consumer Protection Agency \\ Certificate of Incorporation as an Association}

DEPARTMENT OF FAIR TRADING

THIS IS TO CERTIFY that the undermentioned Association is incorporated in New South Wales under the Associations Incorporation Act, 1984.

Association Name:

Incorporation No:

Date of Incorporation:

Issued and given under my hand this twelfth day of December, 2002.

INC9878960

12 December 2002
THE EMT INTERNATIONAL ASSOCIATION INCORPORATED

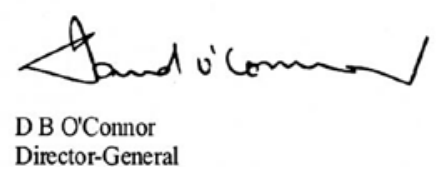

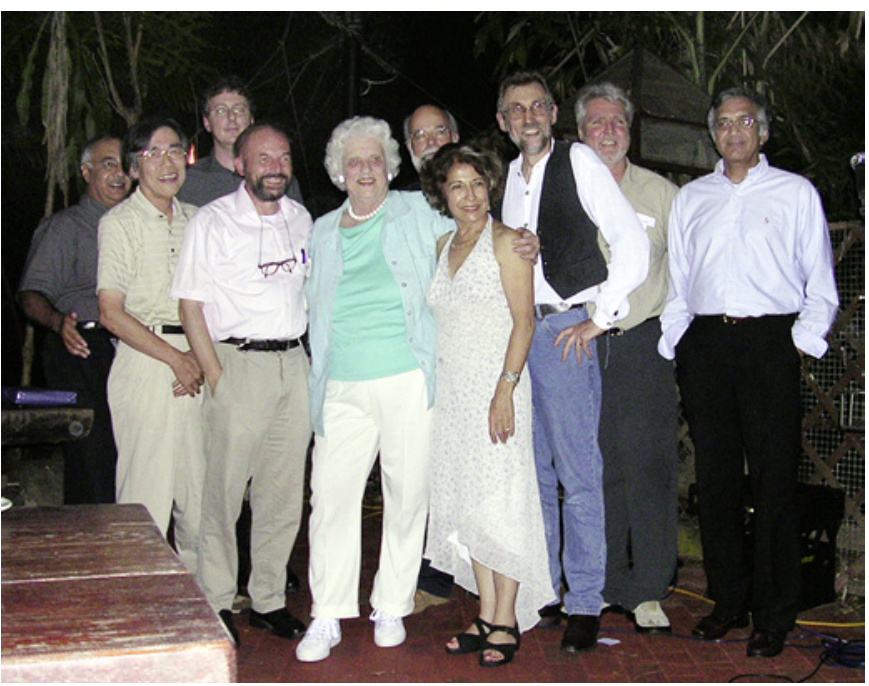

Fig. 2. EMT enthusiasts in its early days. Photo taken of International Committee members for the first TEMTIA meeting in Port Douglas, Australia, 2003 (courtesy of Ros Barrett-Lennard from Magic Touch Consultancies). From left to right: Shoukat Dedhar, Masatoshi Takeichi, Guy Lyons, Jean Paul Thiery, Betty Hay (Chair), Hans-Werner Denker, Mina Bissell, Don Newgreen, Rik Thompson, and Suresh Mohla.
Magic Touch Consultancies who organized it with so much charm and charisma. This was TEMTIA-1, and in 2022 we hope we will see TEMTIA-10 in Paris, 20 EMTfilled years later (note: TEMTIA-10, initially scheduled for 2021, has been postponed to 2022)! The first meeting was truly memorable, although they have all been great. It was so well received by the international community, who came from all over the world, despite the very meagre reimbursal possible for speakers. I recall there were only a handful of Australian speakers in the whole 3-day meeting (https://temtia.org/Files/EMTMeetings/2003.pdf), the highlight for me being an electrifying debate on how best to define EMT; and whether EMT was essential for initiating carcinoma invasion, which took place in a crowded and hot room away from the late afternoon pleasures of the environment. So much participation! After a full day conferencing, this long running and packed debate ahead of the conference dinner said a lot about the passion and commitment in this field. By the way, the only molecular feature that could get a look in was possibly the FGFR splice isoforms and it was felt that mesenchymal cells must be migratory in 3D. Many of those who attended TEMTIA-1 are still active in our field.

Don: In the mid 1990s Hans-Werner Denker asked me to edit an issue on EMT for Acta Anatomica (the journal 




Fig. 3. Poster for the first TEMTIA meeting held in Port Douglas, Australia in 2003.

later changed its name to Cells Tissues Organs) since I had a few publications on that archetypal EMT, that of the neural crest, and I guess he knew of me from my time in Germany. I solicited reviews from a lot of scientists and they were very generous so this ballooned into a double issue with an introductory overview by Betty Hay [Hay, 1995]. It turned into a colossal job of editing. Fortunately, it seemed to be pretty well received. Getting together with Rik Thompson in Melbourne in the early 2000s, somehow the idea of an EMT meeting bubbled up as a kind of face-to-face version of the same thing. "TEMTIA Inc." itself was established as a cover organization so Rik and I would not be individually responsible financially if the meeting turned out to be a failure! That was a real possibility because we were not underwritten by societies or major grants or bequests - probably because EMT seemed too novel and too risky - how times have changed! I wrote invitations to the top 40 international EMT-related scientists, expecting about 15 positive responses at the most. Instead, 39 said yes immediately. We could have been in deep trouble financially because we had nowhere near the money to cover this, but fortunately QANTAS donated a first-class seat for Betty Hay (though that required considerable arm-twisting and stress hormones through the roof) and most other speakers said they'd pay their own way, such was the timeliness of this meeting. When the question arose as to whether there might be another EMT

Interview with TEMTIA Co-Founders meeting, it required all of about ten seconds to obtain a unanimous vote of Yes!

G.S.: The current EMT special issue is hosted by CTO (Cells Tissues Organs), a journal previously known as Acta Anatomica and which has already published six such special issues in the past, counting the first issue as double issues (Vols 154:1, 156:3, 179:1-2, 185:1-3, 193:1-2, and 203:2;https://www.karger.com/Journal/ SpecialTopicIssues/224197). Recently, there have been many journals publishing EMT-related special issues. What has been your relationship with CTO and what do you think about this journal's role in promoting EMT research?

Rik: The relationship with CTO was enthusiastically nurtured by Hans-Werner Denker (a recently retired coEditor in Chief; together with Arthur English), and is precious to TEMTIA. The first two issues in Acta Anatomica, edited by Don, predated my entry in the field; however, I have been involved along with Don in all of the others, and I am delighted to be co-guest editor with Guojun in the current Special Issue. I have also co-led other EMT Special Issues, such as in Clinical and Experimental Metastasis and Journal of Mammary Gland Biology and Neoplasia, and there have been several others, which has only added to the exposure and opportunities for our members to publish their work, views, and reviews. This is a huge field with approximately 100 PubMed citations per week still, so there is no shortage of interesting material and input for the Special Issues, and they are well read and well cited. The close relationship between CTO and TEMTIA has led to a special bond which we celebrate after each biennial TEMTIA conference with a Special Issue related to that conference. They have supported all of our meetings at one level or another. I hope we continue to keep up this tradition.

Don: From the previous answer you can see that CTO and in particular Hans is owed a debt of gratitude - it was his foresight in immediately picking up on the seminal importance of Betty's pioneering work that started the ball rolling. I have been an editor for CTO for years in the developmental biology field, so the EMT special editions were and are a natural fit. And CTO got in on the ground floor with EMT, so I guess that imitation by other journals is the highest form of flattery.

G.S.: To Hans, why did you get interested in EMT research? Did you help publish the first EMT special topic issue (and several subsequent ones) in CTO and promote EMT research in your capacity as an editor or a scientist?

Hans: Rik and Don have said very friendly words about my role in kicking off this series of previous special

Cells Tissues Organs 2022;211:252-260 255 
topic issues of Acta Anatomica and CTO from 1995/1996 on, and what this may have meant generally for the start of the EMT research wave and TEMTIA. I imagine that readers may now ask themselves: "Why did Hans do this at all?" So let me put this into some appropriate context. This whole initiative had to do with my own research interest, and in this sense the effort I have made to promote discussions on EMT in the journal was not an altruistic act at all but was very egoistic. My own research interest was and is in the fields of development and embryo implantation. Until about the 1980s, most implantation research used to focus on endocrinology, whereas cell biological questions were rarely asked. I had myself worked on involved proteinase systems. Functional experiments with proteinase inhibitors had shown quite impressively that a specific proteinase system does play a significant role in the initial phase, until the trophoblast of the blastocyst attaches to the endometrium. However, it turned out that this enzyme system does not seem to play a role in the subsequent invasion of the trophoblast through the uterine epithelium. This made us redirect our focus on the cell biology of the two interacting epithelia, the trophoblast and the uterine epithelium.

Fittingly, around the early 1980s, cell biologists working in various other systems had started to develop an interest in epithelial cell polarity and to compare it with the (different) structural organization of mesenchymal cells, and to ask about the consequences this has for cell behaviour. Betty Hay's great role has already been highlighted above. I became infected with these upcoming ideas, and so I could not resist asking, for example, in a 1983 review [Denker, 1983], a cell biological question which was considered quite non-canonical by my fellow reproductive biologists: Do the observations we had at that timepoint "indicate that, perhaps, the uterine epithelium loses or even reverses its functional (apico-basal) polarity, after proper hormonal conditioning, when the trophoblast contacts it?" I started reading papers on other processes in development initiated by two epithelia establishing contact with each other via their apical cell poles, the so-called embryonic fusion processes (like the fusion of the palatal shelves, as studied by Betty Hay), and I confronted the Anatomische Gesellschaft (Anatomical Society) with these new cell biological concepts (epithelial cell polarity, comparison of embryo implantation with embryonic fusion processes, EMT) at a main lecture given in its 1985 meeting in Prague (Verh. Anat. Ges. 80, Prague, 1985; Anat. Anz. Suppl. 160, 93-114, 1986). However, since this publication was in German, it was not widely noticed in the international community.
It was also around that time that I met Don at a conference here in Germany, and I remember well that I discussed with him the apparent cell biological connections between EMT as going on in the emigrating neural crest cells (which he was studying) and the fusion of the neural folds, normally accompanied with this process. Although Don was more interested in the crest itself, I recall he agreed that the idea about a connection between the two processes was intriguing. In order to start a discussion within the international community on an application of the emerging EMT concepts to embryo implantation research, my group then decided to organize an international workshop which was held at Heidelberg in 1986, attended by an unusual mixture of cancer biologists and reproductive biologists, and here this idea of an application of the novel EMT concept to embryo implantation was really coined, published in book form some years later [Denker and Aplin, 1990]. This also initiated quite a number of follow-up studies, diving more deeply into the secrets of the cellular processes going on in these two interacting systems, in my lab and later on also in others. In my lab, the leading idea was that the interacting partners, trophoblast and uterine epithelium, make use of certain elements of an EMT program leading to changes in cell behaviour [Denker, 1993, 2016]. Similar work from other labs concentrated just on aspects of epithelial membrane properties [Murphy, 2004]. Other authors have recently adopted the EMT idea explicitly in their studies on implantation, although not citing its origin [Uchida et al., 2016].

G.S.: Elizabeth (Betty) Hay is generally credited with having started this field. Who else, in your opinion, has played an instrumental role in (and deserves the credit for) pushing this field forward in its early days?

Rik: There is no question of the pioneering role in EMT that Betty Hay is appropriately credited with, and we were delighted that she was our opening plenary speaker at the first of our TEMTIA conferences in Port Douglas (2003). Betty also presented at the 2005 conference in Vancouver, although a decline in her health was already visible, and her wonderful life and career was celebrated at the third TEMTIA meeting in Kraków, Poland (2007). We also acknowledge her outstanding achievements and critical role in our field with the prestigious Betty Hay Award for emerging female EMT scientists at each TEMTIA meeting since then. Certainly, there were other important contributors such as Don Newgreen himself in neural crest, for which he worked collaboratively with Jean Paul Thiery in Paris in the early 1980s, and Jean Paul really became the pioneer of cancer EMT 
from the 1980s. Ray Runyan from Tucson, Arizona, USA was clearly an early player in cardiac development in the 1980s, as was Hans-Werner Denker for embryo implantation in regards to both trophoblast invasion and endometrial receptivity. I believe also that the hub around Marc Mareel in Belgium and Walter Birchmeier in Germany contributed very significantly to our understanding of cancer EMT in the early days, and seeded an ongoing expertise in Europe with very many worthy participants.

Don: An example of EMT - Zwischenstrang aka neural crest - was first depicted in the $1860 \mathrm{~s}$ by Wilhelm His, but its wider importance not realised. Betty Hay's seminal role is completely merited; from the late 1960 s she recognised the crucial importance of these events and supplied the name EMT (though initially the T meant Transformation). There were not that many EMTers even in the early 1980s, but from Betty's lab, I think Gary Greenburg should be mentioned. The 1982 Greenburg and Hay paper [Greenburg and Hay, 1982] showed experimentally the induction in vitro of EMT in previously epithelial cells. This was a towering achievement. Also, Raymond Runyan began exploiting the cardiac cushion EMT workhorse. Ray continues as a tenacious and productive figure in EMT to this day. Of course, the centrality of control of cell adhesion for EMT was dependent on Masatoshi Takeichi's seminal studies on cadherins, which paralleled the codification of EMT by Betty. The extension in the early 1990s into the transcriptional control of EMT was a crucial technical and intellectual step, for which we are indebted to Angela Nieto. These scientists were all essentially developmental biologists, but all recognised the relevance of EMT to cancer research. Something like this was obvious to embryologists for a century, but the early EMTers seemed to have had a disappointing lack of success at tapping the cancer research pot of gold! It took my early collaborator Jean Paul Thiery in the 1980s, clutching the gospel of developmental EMT, to bravely jump from development to oncology, and finally grab cancer biologists by the scruff of the neck and force them to see the light. It was really from this point that the EMT field commenced its exponential growth.

G.S.: How about yourselves? What do you think you have contributed research-wise to this field, especially in its early days?

Don: In my 1982 paper [Newgreen and Gibbins, 1982], I defined EMT negatively by arguing that there were four conditions that prevented EMT and the trigger was the last one to change from $\mathrm{E}$ to $\mathrm{M}$, and showed that in the avian crest this was cell-cell adhesion. Betty conveyed me a note of congratulations - by telegram! A follow-up pa- per published in 1985 [Newgreen and Gooday, 1985] showed that the above cell-cell adhesion molecule was calcium dependent, and removal of calcium for even a few minutes could provoke an EMT in the crest cells. Masatoshi had identified cadherins not too long before this, so it was timely. In two papers published in the mid 1990s [Newgreen and Minichiello, 1995, 1996], Joe (Minichiello) and I attempted a dissection of crest EMT, and found that by artificially driving EMT-like change in one cell system (i.e., in cell adhesion or ECM adhesion or cytoskeleton), the other cell systems would also change. In the late 1990s, we published a paper on quail crest EMT and atypical protein kinase-C [Minichiello et al., 1999], and I think this was also the first paper to report this role of aPKCs, now a growth industry coupling Par3, Par6, etc. with aPKCs in EMT in all kinds of cells. This also established a record for sending the manuscript to one journal after another. In a paper published in the early 2000s [Farlie et al., 2001], Peter (Farlie) and I devised a genetic approach to identify a new "neural crest defect" gene by cross-referencing genes in the human DiGeorge Syndrome critical region against mouse E10.5 branchial arch cDNA library (the branchial arch where and when DiGeorge must "go wrong") against quail E3.5 branchial arch library (for cross-species sequence conservation as an index of importance). We turned up Ypel1 (we also found another three Ypels in human genome). I am still really angry about this because we could not get grants to follow up. And Ypel1 is one of the most conserved genes in creation (human:avian conservation 100\%), so it's got to be important for something, perhaps MET. So, this avenue died!

Rik: I did come on board a little later, although still somewhat early especially regarding TEMTIA. First and foremost, I think, was illustrating that EMT (vimentin) associated with highly invasive versus non-invasive human breast cancer cell lines [Thompson et al., 1992], which was built on a background of interest in matrix metalloproteinases (MMPs), especially MT1-MMP and MMP2, which partition along EMT lines. This relationship has stood the test of time and underpins the current molecular (transcriptome-level) subgroups in these cell lines (there are over 100 lines now studied in different ways) and relates to both clinical subtypes and mammary developmental states. This has been a mainstay backdrop to my ongoing research interests and that dichotomy of cell phenotype and function has been exploited in thousands of studies since. Alongside this was my passion and compulsion for the society of science in this field, the collegiality of collaboration on a global scale, and the orga- 
nizational structures that would facilitate this for EMT research. This is reflected in the continuity of TEMTIA as an international collective with biennial TEMTIA meetings, as well as the special issues and reviews, all of which bring stability and conviviality to this field.

G.S.: EMT has now become a mainstream concept and there have been many primary research papers and reviews written on this subject. If you have any advice to give, what is one thing that this field is still missing after 40,000 publications?

Rik: A pressing issue is to resolve the controversy on the contribution played by EMT in metastasis [Williams et al., 2019]. There are compelling data to support an important role in numerous studies both clinical and preclinical, as has been the case for decades; however, it has been difficult to show more than a partial contribution in lineage tracing studies, and some have been totally negative. A number of explanations have been levied, and they are all quite likely; however, it would be great to get a definitive demonstration of this, especially since the supportive data is so compelling. Also, with the emergence of stable EMP (epithelial-mesenchymal plasticity) hybrid phenotypes that are enriched in metastatic potential, it will be important to see how these fit on the therapy resistance spectrum seen between the epithelial (low resistance) and mesenchymal (high resistance) poles, as explored in more detail in Jolly et al. in this latest EMT special issue.

Don: One thing I would like to see further explored is the information flow between the various EMT genomic control elements (transcription factors, etc.) and the motor molecules of EMT cell behaviour (adhesion molecules, cytoskeletal molecules, etc.). It is generally pictured simplistically as the former acting as the "managing directors" dictating the synthesis of the latter, which function as the workers on the "factory floor", with orders proceeding top-down, from board room to factory floor. I think that the information flow is much more complex than this, and the nature, timing, and importance of bottom-up information might be worth a look. Additionally, the role of the broader biophysical environment in the modulation of EMT needs even further exploration; clearly the EMT state is highly reactive depending on these physics of interactions. Finally, a particular hope of mine is the construction of useful multi-level, multimodal network mathematical models of EMT.

G.S.: It is great to see that the EMT concept unites researchers who would otherwise be working with quite different aspects of biology and be taking different investigative approaches. Like any conceptual framework in science, however, it runs the risk of becoming dogmatic when it tries to explain too much. Do you think EMT is such a concept and why?

Rik: Never! The TEMTIA meetings and CTO Special Issues provide clear evidence of the advantages of crossdisciplinary interactions for EMT researchers from these large disciplines in terms of technology understanding model systems and a unified set of descriptive guidelines. Certainly, it is a problem to try at this stage to be dogmatic about EMT, due to the heterogeneity and complexity. But the shared interaction across the various disciplines has helped us appreciate that! I am clearly very positive about the benefits of interaction as initially envisaged by Don in creating TEMTIA: Cancer - Pathology - Development, and I do expect that there are major breakthroughs that will come soon with the increased technology and activity, and will provide a rationalisation for the huge investment that has been made in understanding EMT.

Don: This is always a problem with all dominant paradigms, so beware. For example, at one stage in the ascendancy of EMT, it became viewed as being a kind of flipflop switch with an implied lack of a (meta)stable middle position. This I think stemmed from too exclusive use of the avian neural crest as representative of all EMTs, and I was as much responsible for this simplistic view as anyone. Fortunately, others saw the light and introduced the partial EMT or hybrid state concept as being more widely applicable to developmental EMTs and to cancer and wound healing EMTs. Betty Hay's EMT concept holds, but it is viewed with much greater subtlety and nuance now. And we should always keep in mind that EMT is defined by dynamic changes in cell behaviour, not just by expression (or suppression) of one or a few genes. So, in your system of choice, even if you detect modulation of famous "EMT genes," you still have to go back to verify EMT with functional assays.

Hans: I think Don's remark about the partial EMT or hybrid state concept is worth being considered more widely. Interestingly, it fits quite nicely the conclusions we arrived at in our studies on the embryo implantation story. The experimental facts we have been able to find seem to indicate that the uterine epithelium, for example, when entering the state of receptivity for trophoblast attachment and invasion, uses elements (only elements, although typical ones) of an EMT program, but not the full program. These epithelial cells do not give up their epithelial nature completely; that would be much too dangerous. What is going on at embryo implantation appears to be that the two interacting systems, that of the invading 
trophoblast and that of the maternal host tissue, apply just certain parts of EMT processes [Denker, 1993, 2016].

G.S.: In your expectation, what kind of discovery in the near future would constitute the biggest contribution that the EMT research field can make to biomedical sciences?

Rik: For me the holy grail will be an EMT-targeted therapy that provides a benefit clinically in cancer treatment, most likely working in conjunction with standard therapies, targeted therapies, all the new revolution of immunotherapy [Redfern et al., 2018]. This would be huge catalyst for the further work required in terms of understanding EMT across development, wound healing, and cancer.

Don: This would have to be the production of effective therapeutics for long-term control of EMT-like changes in cancer metastasis.

G.S.: What is one thing you want people to know about yourself, outside science?

Rik: This is a tricky question, but the most immediate answer would be my love for sailing. I feel so lucky to have discovered this somewhat later in life. If you're reading this, give it a go - you'll never look back!

Don: Several things. That I have a passion for Blues and Baroque music. And dreadnought battleships. And woodwork.

G.S.: To Don, have you taken up any new mission since your retirement?

Don: I was born into a fortunate generation, as John Lee Hooker says, I had Mr Lucky standing over me. Yet the prospects for younger people (including young scientists) are not so optimistic, for very good reasons. So, I have taken to bothering politicians with unwanted advice! I am also attempting to help connect lower socioeconomic level secondary students with scientific mentors; I think that often sheer ability in such students requires a push in self-confidence that a mentor can provide. Oh yes, and I have resumed wood-working.

G.S.: Thank you Rik, Don, and Hans, for sharing your experience and your thoughts on EMT and TEMTIA, especially under the current difficult situation we are all facing.

\section{Note}

The interview was conducted virtually throughout 2020 and in early 2021. Rik: Erik Thompson; Don: Donald Newgreen; Hans: Hans-Werner Denker; G.S.: Guojun Sheng, the interviewer. Rik currently is a Professor in

Breast Cancer Research at Queensland University of Technology. Don recently retired from Group Leader position at Murdoch Children's Research Institute and has taken up the new cause of science outreach and mentoring for underprivileged students. Hans is a retired Professor of Anatomy and Developmental Biology at University of Duisburg-Essen and a former Editor-in-Chief of Cells Tissues Organs.

\section{Acknowledgement}

We would like to thank Ros Barrett-Lennard for the photo shown in Figure 2 and Dr. Jean Paul Thiery for catalyzing historical recollection of EMT.

\section{Conflict of Interest Statement}

The authors have no conflicts of interest to declare.

\section{Funding Sources}

This interview contains no primary research data. It was conducted virtually and was not commissioned by any external funding agency. The authors acknowledge the support from their respective institutions for time commitment necessary to conduct and complete this interview. The IRCMS (host institute of G.S.) receives funding from the Japanese government and Kumamoto University. The Translational Research Institute (host institute of E.T.) receives funding from the Australian Government.

\section{Author Contributions}

G.S. conducted the interview. E.T. and D.N. responded to interview questions. H.-W.D. provided historical context to the first EMT special issue. All authors proof-read the final manuscript.

References

Cells Tissues Organs 2022;211:252-260 DOI: $10.1159 / 000518250$
Ackland ML, Newgreen DF, Fridman M, Waltham MC, Arvanitis A, Minichiello J, et al. Epidermal growth factor-induced epithelio-mesenchymal transition in human breast carcinoma cells. Lab Invest. 2003;83:435-48.

Denker H-W, Aplin JD Trophoblast Invasion and Endometrial Receptivity : Novel Aspects of the Cell Biology of Embryo Implantation, $\mathrm{Vol}$ 4. New York: Plenum Medical Book Co.; 1990.

Denker HW. Basic aspects of ovoimplantation. Obstet Gynecol Annu. 1983;12:15-42.

Denker HW. Implantation: a cell biological paradox. J Exp Zool. 1993;266:541-58. 
Denker HW. Implantation: Cell biology of embryo penetration route revisited. Am J Reprod Immunol. 2016;76:429-31.

Farlie P, Reid C, Wilcox S, Peeters J, Reed G, Newgreen D. Ypel1: a novel nuclear protein that induces an epithelial-like morphology in fibroblasts. Genes Cells. 2001;6:619-29.

Greenburg G, Hay ED. Epithelia suspended in collagen gels can lose polarity and express characteristics of migrating mesenchymal cells. J Cell Biol. 1982;95:333-9.

Hay ED. An overview of epithelio-mesenchymal transformation. Acta Anat (Basel). 1995;154: 8-20.

Minichiello J, Ben-Ya'acov A, Hearn CJ, Needham B, Newgreen DF. Induction of epitheliomesenchymal transformation of quail embryonic neural cells by inhibition of atypical protein kinase-C. Cell Tissue Res. 1999;295: 195-206.
Murphy CR. Uterine receptivity and the plasma membrane transformation. Cell Res. 2004;14: 259-67.

Newgreen D, Gibbins I. Factors controlling the time of onset of the migration of neural crest cells in the fowl embryo. Cell Tissue Res. 1982; 224:145-60.

Newgreen DF, Gooday D. Control of the onset of migration of neural crest cells in avian embryos. Role of $\mathrm{Ca}++-$ dependent cell adhesions. Cell Tissue Res. 1985;239:329-36.

Newgreen DF, Minichiello J. Control of epitheliomesenchymal transformation. I. Events in the onset of neural crest cell migration are separable and inducible by protein kinase inhibitors. Dev Biol. 1995;170:91-101.

Newgreen DF, Minichiello J. Control of epitheliomesenchymal transformation. II. Cross-modulation of cell adhesion and cytoskeletal systems in embryonic neural cells. Dev Biol. $1996 ; 176: 300-12$
Redfern AD, Spalding LJ, Thompson EW. The Kraken Wakes: induced EMT as a driver of tumour aggression and poor outcome. Clin Exp Metastasis. 2018;35:285-308.

Thompson EW, Paik S, Brünner N, Sommers CL, Zugmaier G, Clarke R, et al. Association of increased basement membrane invasiveness with absence of estrogen receptor and expression of vimentin in human breast cancer cell lines. J Cell Physiol. 1992;150:534-44.

Uchida $\mathrm{H}$, Maruyama T, Masuda $\mathrm{H}$, Uchida $\mathrm{S}$, Miki F, Hihara H, et al. How to Create an Embryo Penetration Route. Am J Reprod Immunol. 2016;75:326-32.

Weston JA. The migration and differentiation of neural crest cells. Adv Morphog. 1970;8:41114

Williams ED, Gao D, Redfern A, Thompson EW. Controversies around epithelial-mesenchymal plasticity in cancer metastasis. Nat Rev Cancer. 2019;19:716-32. 